\title{
Lock in and Switch: Asymmetric Information and New Product Diffusion
}

\author{
Luís M B Cabral* \\ New York University and CEPR
}

April 2007

\begin{abstract}
Many new web-based services are introduced as free services. Depending on the seller's business model, some remain free in the long run, while others switch to pay mode at some point in time. I characterize the relation between buyers and a new service seller when the former are uncertain about the latter's business model. I derive a natural signalling equilibrium where the seller plays a "lock-in-and-switch" strategy, while buyers play a "wait-and-see" strategy. I show the equilibrium entails diffusion even though consumers are identical and equally aware of the new service's existence.
\end{abstract}

${ }^{*}$ Stern School of Business, 44 West 4th Street, New York, NY 10012; lcabral@stern.nyu.edu. (Address during AY2006-2007: Department of Economics, Yale University, 37 Hillhouse Avenue, New Haven, CT 06520.) I thank Jim Anton, Kyle Bagwell, Yuxin Chen, Judy Chevalier, Tülin Erdem, Mike Katz, Alessandro Lizzeri, Barry Nalebuff, Roy Radner, and seminar participants at NYU and ECARES for useful comments and suggestions with reference to a previous (and substantially different) version of this paper. The usual disclaimer applies, especially considering the differences between this and the previous draft of the paper. 


\section{Introduction}

The economic and social impact of the Internet can hardly be overstated. One of the many effects of the "information highway" is the wealth of new services that it allows for - sometimes web-based versions of existing services, sometimes entirely new services. Examples include web-based email, news, blogging, on-line radio and $\mathrm{TV}$; and various types of organized information (dictionaries and encyclopedias, directions, restaurant reviews, financial information, and so forth).

Frequently, new services are offered for free. Examples include JumpTV, Vindigo, AvantGo or Google mail. However, a zero introductory price is not necessarily a permanent feature: at some point, Vindigo and JumpTV started charging for their services; AvantGo and Google mail are still free. ${ }^{1}$

The variety of pricing strategies reflects the variety of business models followed by new service suppliers. Sometimes revenues are primarily based on consumer subscription fees, in which case a zero introductory price is most likely a temporary offer. In other cases, revenues are primarily based on advertising or referral fees charged to third parties, in which case consumers can expect zero prices to be a permanent feature. In most cases, however, revenues are a combination of advertising and subscription revenue. In fact, it is common for sellers to offer two options, a free option and a pay option, with different levels of service and advertising included.

From a consumer's point of view, whether to start using one of these services is a difficult decision problem. A starting cost must normally be incurred: getting acquainted with how the service works, downloading software, perhaps making some complementary investment. Against this cost - typically a one-time sunk cost potential adopters must weigh an uncertain benefit: perhaps the service will be offered for free indefinitely, perhaps the seller will start charging for it at some point in time.

In this paper, I characterize the strategic interaction between seller and buyers in a situation of asymmetric information. Consumers are uncertain about the seller's business model, a feature that I model by assuming the seller can be of two types: $\mathrm{H}$ and L. A type $\mathrm{H}$ seller, under complete information, would optimally set a strictly positive price - the seller's business model is to charge consumers. A type L seller, in turn, has marginal cost sufficiently negative that its optimal price is zero. The idea of a negative marginal cost captures the business model whereby sellers earn revenue from a third party either in the form of advertising or business referrals.

I consider a "natural" Bayesian equilibium and show that it involves gradual separation between the two seller types. For a period of time, sellers pool at a price

\footnotetext{
${ }^{1}$ AvantGo offers a premium service for a fee. In Section 4, I consider the case when a seller's set of options extends beyond the choice of free and pay modes.
} 
of zero. Eventually, a high-cost seller type switches to its monopoly price. Until then, potential adopters gradually enter, by paying the necessary sunk cost and thus becoming "locked-in" to the seller.

In other words, the seller - in particular the high-cost seller — plays a "lock-inand-switch" type of strategy: set prices at zero, wait while buyers gradually come in, then switch to pay mode. Buyers, in turn, play a "wait-and-see" strategy: wait while price is at zero and gradually update the belief that the seller's business model is one of charging third parties, not the buyers.

Previous economic research has dealt with new product introduction under asymmetric information. This literature typically derives separation equilibria, whereby the introductory price indicates to consumers the firm's level of cost or quality. If the length of commitment to price is very short, however, than no pure separation equilibrium exists. I focus in the case of no commitment to prices by considering the extreme case of continuous time; and show that a "gradual separation" equilibrium exists, whereby sellers pool at zero price for a while and the high cost seller eventually switches to a positive price.

One of the interesting characteristics of the equilibrium I consider is diffusion. Specifically, even though all consumers are identical and equally aware of the existence of the new service, different consumers adopt the new service at different moments in time. In this sense, I provide an explanation for diffusion that differs from the traditional models based on word-of-mouth effects or consumer heterogeneity.

\section{Model}

The central players in my model are a seller and a continuum of consumers. I am interested in examining the case when the seller has no ability to commit to future prices. In order to do so, I consider the extreme case of continuous time and assume the seller must set $p(t)$ for all $t \in[0, \infty)$. I also assume that both seller and buyers discount the future according to an interest rate $r$.

All consumers have the same utility function. In order to start using the new service, a consumer must pay a sunk cost $s / r$, so that $s$ represents the equivalent flow of cost the new consumer must commit to. Upon adoption, a consumer receives a surplus rate of $\mu(p)$ at each moment in time, where $p$ is price at that moment in time. (I could consider a more complicated model including the decision of how much to consume of the service, but all that I need is the value of consumer surplus as a function of price.)

A central feature of the model is incomplete information: consumers are uncertain about the seller's business model. I model this feature by assuming that the 
seller can be of two types: $\mathrm{H}$ and L. A type $\mathrm{H}$ seller as zero marginal cost. Given a set of consumers and complete information, an $\mathrm{H}$ seller would optimally set a strictly positive price - the seller's business model is to charge consumers. A type L seller, in turn, has marginal cost sufficiently negative that its optimal price is zero. The idea of a negative marginal cost captures the business model whereby sellers earn revenue from a third party either in the form of advertising or business referrals. Note that an optimal price of zero is not a knife-edge situation as long as negative prices are not feasible. The assumption is then that the seller's cost is sufficiently negative that the optimal price (under complete information) would be negative.

The seller's type is the seller's private information; consumers only know the distribution of types, holding a prior $\rho$ that the seller is of type L. Let $\pi^{\star}$ be a type $\mathrm{H}$ seller's profit per consumer if it sets its (static, complete information) optimal price. (Notice that, since all consumers are identical, optimal price is independent of the number of consumers.) Let $\mu^{\circ}$ be consumer surplus under zero price, and $\mu^{\star}$ consumer surplus when price equals seller H's optimal price. I make a fundamental assumption regarding consumers' adoption cost in relation to consumer surplus:

\section{Assumption $1 \quad \mu^{\star}<s<\mu^{\circ}$.}

In other words, under complete information consumers would not buy from a highcost seller, but they would from a low-cost seller. If this assumption is violated, then the problem is trivial. Specifically, if $s$ is lower than $\mu^{\star}$ then the only equilibrium is for all potential adopters to adopt at time zero. If, on the other hand, $s$ is greater than $\mu^{\circ}$, then the only equilibrium is for consumers never to adopt.

\section{Diffusion equilibrium}

The main result in the paper is that there exists a diffusion equilibrium to the game presented in the previous section. The nature of this equilibrium is that a type $\mathrm{H}$ seller will set zero price for some time and then switch to its optimal static monopoly price. Consumers, in turn, gradually pay the "entry" cost required to consume the product. In other words, the seller plays a "lock-in and switch" strategy, whereas consumers play a "wait-and-see" strategy.

Proposition 1 There exists a Bayesian equilibrium characterized by the following behavioral strategies. Let

$$
T=-\frac{\left(s-\mu^{\star}\right) \ln \rho}{\left(\mu^{\circ}-s\right) r} .
$$

An $L$ seller always sets zero price. An $H$ seller starts pricing at zero; for $t<T$ and conditional on having set zero price in the past, an $H$ seller switches to monopoly 
price at time $t$ with probability density

$$
\theta(t)=\frac{-\frac{\ln \rho}{T} \exp \left(\frac{\ln \rho}{T} t\right)}{1-\rho+\exp \left(\frac{\ln \rho}{T} t\right)} ;
$$

finally, for $t>T$ an $H$ seller sets monopoly price.

For $t<T$ and conditional on having observed zero price in the past, a potential adopter enters with probability density

$$
\lambda(t)=\frac{r \exp (r T+r t)}{1-\exp (r T+r t)},
$$

where $\rho$ is the initial belief the seller is of type L. For $t>T$, a potential adopter enters if and only if price is zero.

In order to better understand the nature of the equilibrium, Figure 1 depicts the cumulative distribution functions of the seller and buyers' strategies. Specifically, $F(t)$ is the probability that an $\mathrm{H}$ type seller will have switched to pay mode by time $t$, whereas $Q(t)$ is the fraction of consumers who adopt by time $t$ conditional on the service being offered for free up until then. In the proof of Proposition 1, which I include in the Appendix, I show that

$$
F(t)=\frac{1}{1-\rho}\left(1-\exp \left(\frac{\ln \rho}{T} t\right)\right),
$$

so that the hazard rate $\theta(t)$,

$$
\theta(t) \equiv \frac{f(t)}{1-F(t)},
$$

where $f(t)$ is the density corresponding to $F(t)$, is given by the expression in the proposition. Regarding the rate of adoption, I show that

$$
Q(t)=\exp (r(t-T)),
$$

so that the hazard rate $\lambda(t)$,

$$
\lambda(t) \equiv \frac{q(t)}{1-Q(t)},
$$

where $q(t)$ is the density corresponding to $Q(t)$, is given by the expression in the proposition.

The equilibrium in Proposition 1 involves mixed strategies. I derive the equilibrium in the usual way: the seller's indifference condition implies an adoption path for buyers, and the buyers' indifference condition implies a price switch distribution. 


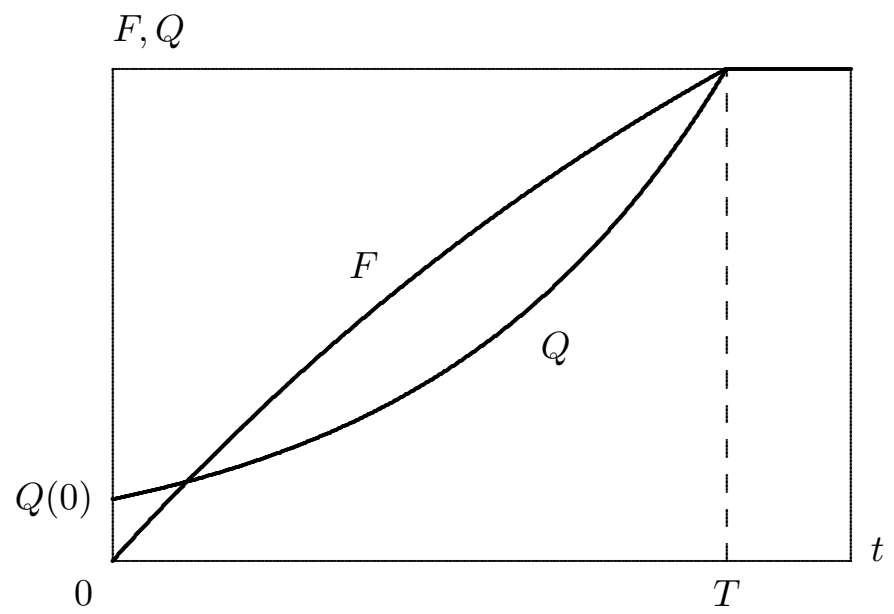

Figure 1: Equilibrium cumulative distribution functions.

Specifically, in order for an $\mathrm{H}$ seller to be indifferent between switching to pay mode and continuing with zero price there must be a "promise" that by continuing with zero price the installed base will increase. Since the opportunity cost of keeping price at zero is greater the greater the installed base, the increase in installed base itself must be greater the greater the installed base. This implies an exponential growth path for $Q$ :

$$
Q(t)=Q(0) e^{r t}
$$

In order for consumers to be indifferent between adopting now or at a future moment in time, $F$ must be given by

$$
F(t)=\frac{1}{1-\rho}\left(1-\exp \left(\frac{\mu^{\circ}-s}{s-\mu^{\star}} r t\right)\right) .
$$

Imposing $F(T)=1$, we get the value of $T$. Finally, this allows us to pin down the value of $Q(0)$.

The intuition for the expression of $F$ is not immediately apparent. Note however that the hazard rate $\theta(t) \equiv f(t) /(1-F(t))$ increases exponentially. This is intuitive as the value of $\theta(t)$ corresponds to the consumer's option value of waiting: by waiting for a period $d t$, there is a chance $\theta(t)$ that the seller will switch to pay mode, in which case the consumer will have optimally saved the sunk cost $s / r$. Now, the longer the service is offered for free the more convinced the consumer is that the seller's business model is one of zero price. In order to balance this increase value from adoption we must also increase the value of waiting - which we do by increasing $\theta$. 
It can be shown that $F$ is concave and $Q$ is convex (for $0<t<T$ ), so the qualitative properties of Figure 1 are general. Regarding the value of $T$, the comparative dynamics produce the expected results: $T$ tends to zero as $\rho$ tends to 1 , and to infinity as $\rho$ tends to zero. Moreover, $T$ is increasing in $s$ and decreasing in $\mu^{\circ}, \mu^{\star}$ and $r$.

\section{Extensions and related work}

There is a very extensive economics literature on the adoption of new goods. There is also a very extensive literature on the implications of asymmetric information between seller and buyers. In this section, I try to relate my model to these literatures. I also consider alternative interpretations and extensions of my basic model.

- Relation to the diffusion literature. One interesting feature of my equilibrium is that it induces diffusion, that is, not all adopters start purchasing at the same time. At the risk of oversimplifying, the previous literature on new product diffusion can be summarized into two classes of theories. One is based on imperfect knowledge of product availability and some form of word-of-mouth communication whereby later adopters learn from earlier ones. The second one is based on adopter heterogeneity and a declining trend in adoption price: high valuation adopters buy earlier, low valuation adopters buy later. ${ }^{2}$ In my model, diffusion results from the consumers' wait-and-see strategy, not from adopter heterogeneity. Naturally, my assumption of consumer homogeneity is not particularly realistic. Moreover, in a richer model that featured heterogeneous consumers I would expect the order of adoption to be monotonic in consumer type. However, even in that case an important portion of diffusion would be due to consumer uncertainty about the seller's business model.

An additional difference with respect to the diffusion story based on adopter heterogeneity is that the latter requires that price be declining over time. In my gradual separation equilibrium, however, expected price is increasing over time.

- Relation to the viscous demand and switching costs literature. Radner (2003) and Radner and Richardson (2003) propose models of "viscous demand," the situation when demand adjusts slowly to changes in prices. Radner (2003) proposes an "attention budget" explanation for demand viscosity. As he puts it, "the (potential) consumer cannot be thinking every hour, or even every week, about

\footnotetext{
${ }^{2}$ See Bass (1969) and Jensen (1982) for examples of the former approach; and Griliches (1957), David (1969), Davies (1979) for examples of the latter approach. See also Geroski (2000) for a good survey of this literature.
} 
which long-distance carrier to use. Rather, the consumer rethinks such decisions from time to time, regularly or at some random intervals." If different consumers do their rethinking at different moments of time, then the phenomenon of gradual response to price changes results naturally.

Suppose there is an incumbent firm (e.g., AT\&T) charging price $p$. Suppose that an entrant (e.g., MCI) moves in with a lower price, $p^{\prime}<p$. If consumers are uncertain about the entrant's cost, then we have a situation similar to the adoption of a new service. Specifically, I may reinterpret the adoption of a new seller as a switch from an existing seller. My model then provides an alternative foundation for demand viscosity. Even if consumers have an infinite "attention budget," to use Radner's terminology, they do not switch immediately; rather, they play a "waitand-see" strategy, as shown in Section 3, which in turn leads to gradual adjustment to a lower price set by an entrant - a viscous demand shift.

Continuing with the analogy between new product adoption and seller switching, my model is related to the switching cost literature (see, for example, Klemperer, 1995). However, this literature typically does not consider the information asymmetry that is essential in my model.

Finally, a related series of papers have looked at price dynamics with customer loyalties that create demand inertia. ${ }^{3}$ These papers, like Radner (2003) and Radner and Richardson (2003), take a reduced-form approach to consumer behavior. By contrast, I explicitly model the optimal Bayesian behavior of potential consumers.

- Relation to the "bait-and-switch" literature. Sellers sometimes practice a form of false advertising known as "bait and switch." They advertise a certain good at a certain price, thus enticing consumers to visit their store. But when the consumer visits the seller, that is, when the consumer has paid a sunk search cost, then the seller tries to sell a different product at a different price. Various authors have shown how bait and switch can be an equilibrium strategy. However, they have not considered to role of time as I do in this paper. ${ }^{4}$

The equilibrium of my model shares some of the features of equilibrium bait and switch. Rational buyers know that, with some probability, they will regret having paid the sunk cost required before a purchase. This cost can be a search cost (bait and switch) or one of the investments listed in the Introduction (lock-in and switch). The reason for the regret is asymmetric information regarding the sellers inventory (bait and switch) or some aspect of the seller's business model (lock-in and switch).

\footnotetext{
${ }^{3}$ See Rosenthal (1982), Rosenthal (1986), Chen and Rosenthal (1996).

${ }^{4}$ See Gerstner and Hess (1990), Lazear (1995), Wilkie et al (1998). These papers are inconclusive as to the welfare effects of bait-and-switch, a (currently) illegal activity.
} 
- Relation to the price signalling literature. In a classic paper, Bagwell (1987) showed that, in a two period model of asymmetric information about seller cost, there may exist an equilibrium where first period price signals the firm's cost and therefore expected second period price. ${ }^{5}$ In Bagwell's model, consumers must pay a search cost before visiting a particular seller. In this sense, Bagwell's model addresses the issues considered in this paper: (a) buyers must pay a cost before beginning to enjoy the new service; and (b) buyers are uncertain about future price.

However, there are reasons to believe Bagwell's equilibrium may not exist in many real-world situations. In fact, if the first period is very short and negative prices are unfeasible, then no separating equilibrium exists. Intuitively, a high cost seller would always want to mimic a low cost seller, thus attracting more consumers and then exploiting its enlarged base of captive consumers. If a money burning technology such as advertising is available, then a combination of price and money burning may achieve separation. But imperfect observability or other reasons may limit such a possibility.

In this paper, by considering a model of continuous time I implicitly make the extreme assumption that the seller cannot commit to prices. This implies that price signalling as in Bagwell's model is not feasible. Prices can still signal seller cost but only when such prices are maintained for a period of time. Continuous time also implies that there exist no equilibria with pure separation. Instead, I consider the possibility of semi-separating equilibria whereby types initially pool and gradually separate (according to the cdf $F$ ). Specifically, in my model separation is given by the time spent at zero price, rather than by the price level itself.

There also exists a literature on separation in dynamic models. The classical application of signalling and separation is Spence's job market signalling game, a two-stage game where workers first choose their education level and firms then make job offers. The Riley (1979) outcome of this game is a separating equilibrium whereby a low ability worker makes no investment and a high ability worker makes the lowest investment such that the low ability type has no incentive to mimic. Noldeke and Van Damme (1990) show that this separation equilibrium survives even if firms can make offers before workers finish their investment in education (and workers cannot commit not to accept interim offers). Swinkels (1999) however shows that, if job offers are not publicly observed, then the equilibrium involves either pooling or partial pooling. My result bears some relation to Swinkels (1999) in that it involves a semi-pooling, or semi-separating, equilibrium.

More recently, Janssen and Roy (2002), consider a dynamic model of a durable good with adverse selection. They show that the classical static-game lemons problem disappears when time is taken into account. In equilibrium, both price and

\footnotetext{
${ }^{5}$ See also Bagwell and Riordan (1991), Judd and Riordan (1993).
} 
the quality of the goods traded increase over time. Although my model is one of signalling, not screening, the equilibrium I consider shares some of the features of that in Janssen and Roy (2002), namely the role of time in achieving separation.

- Relation to the learning curve and network effects literatures. The equilibrium presented in Proposition 1 involves introductory pricing. Two of the most popular explanations for this pricing strategy are learning by doing and network externalities. In a two-period model, Spence (1981) and Fudenberg and Tirole (1983) have shown that learning curve effects imply that first period price may be lower than cost - and in fact lower than second period price. ${ }^{6}$ This is very different from my model. In fact, I get introductory pricing even though there is no "physical" link between periods as in the case of a learning curve.

Regarding network effects, Cabral et al (1999) show that it is remarkably difficult to obtain introductory prices in a setting where consumers are aware of the seller's cost and product quality levels. Their central result features increasing prices but a small number of strategic buyers, a situation that is unlikely to be found in the context of web-based services like the ones presented in the Introduction.

\section{Concluding remarks}

The examples considered in the introduction, and other examples of new Internet services, suggest that the free-vs-pay model may be a bit simplistic. First, even if consumers know that a seller will charge for its service, the consumer may not know the exact price that the seller will charge. In terms of my model, this would amount to considering more than two types, that is, different values of marginal cost that would lead to different optimal prices. Alternatively, the consumer may be uncertain about the demand elasticity, so that, even if cost is known, optimal price in not known.

I conjecture that none of these extensions would change the qualitative nature of my results. Specifically, let $\mu_{i}^{\star}$ be the consumers' rate of consumer surplus given that the seller is of type $i$ and sets monopoly price. If there exist seller types $i, j$ such that $\mu_{i}^{\star}<s<\mu_{j}^{\star}$, then I conjecture that the same qualitative features as in Proposition 1 still hold, that is, different seller types pool for a period of time and eventually separate. ${ }^{7}$

\footnotetext{
${ }^{6}$ See also Cabral and Riordan (1994).

${ }^{7}$ The case when more than one type would set a strictly positive price under complete information is a little more complicated. Suppose that both types H and L have a positive optimal price. I conjecture that the equilibrium strategy for the $\mathrm{H}$ type is similar to that in Proposition 1; whereas the $\mathrm{L}$ type switches to pay mode with probability 1 at time $T$.
} 
In addition to multiple types of seller, I could also consider multiple types of buyer. However, one advantage of my assumption of homogeneous adopters is that it highlights the fact diffusion is due to the properties of the equilibrium, not the heterogeneity of adopters.

I could also consider the possibility of the seller offering multiple versions of the service. For example, Eudora 7.0 is offered in three possible versions: ${ }^{8}$

- Paid mode. Includes extra software, person-to-person technical support, and no advertising.

- Sponsored mode. No extra software or person-to-person technical support. Moreover, there is an ad window and up to 3 sponsored toolbar links.

- Light mode. No ad window but fewer basic features than sponsored mode.

So long as the appropriate generalization of Assumption 1 holds, I conjecture that the qualitative nature of the result still holds. In other words, the important feature is that the consumer the consumer would prefer not to incur the entry cost if it knew that the seller was of the high type.

Finally, a fundamental assumption on which my analysis is founded is that firms cannot commit to future prices. In fact, the main difference between my results and Bagwell (1987), who also looks at new product introduction with asymmetric information, is precisely the seller's inability to commit to future prices.

Some Internet services suggest that there may be some degree of commitment on the seller's part. Take for example the following quote from wordpress.com, which offers free blogging software and hosting.

Obviously running a high quality service like WordPress.com costs money somewhere, so when does the ride end and all you freeloaders have to fork up?

Just kidding! We're being very careful not to introduce features right now that we're not willing to commit to providing for free forever. We know the software and the service better than anyone else in the world, so we know what's what.

What is free now will remain free for as long as we're around.

There are some pretty cool things we want to add but which have a higher cost to provide, and once we figure out the details we may make some paid add-ons available, but they'll be optional. ${ }^{9}$

\footnotetext{
${ }^{8}$ http://www.eudora.com/download/, visited on April 16, 2007.

${ }^{9}$ http://faq.wordpress.com/2005/09/28/whats-free/, visited on April 16, 2007.
} 
While promises are just cheap talk, dynamic reputational concerns may lend some credibility to announcements of this type. If commitment to future prices is feasible, then the natural equilibrium would involve immediate separation (as in Bagwell, 1987). The idea is that the cost of promising zero prices in the future is lower (maybe even zero) for the low cost firm, but high for the high cost firm. ${ }^{10}$

However, even if sellers can commit to keep their current offering free, such offer may be worth little if there is a significant rate of service improvement. By keeping those improvements inaccessible to the free version, the perceived or the real value of the free version is degraded, to the point that the seller may be effectively discontinuing the free option. So, ultimately I believe my assumption of inability to commit to future price or quality terms is realistic, and so are the qualitative features of the equilibrium I derive.

\footnotetext{
${ }^{10}$ Interestingly, one site suggested MoveableType as one of the best options in terms of free web development software. When I checked it, I noticed that MoveableType is no longer free, though it charges a reduced fee for individuals and non-profit institutions.
} 


\section{Appendix}

Proof of Proposition 1: In the equilibrium I will consider, an L type seller always sets zero price. For the remainder of the proof, I will focus on the $\mathrm{H}$ type seller and refer to it simply as seller.

In what follows, I derive a mixed-strategy equilibrium. The seller switches to pay mode by time $t$ with probability $F(t)$. Each consumer, in turn, adopts the new service by time $t$ with probability $Q(t)$. Since this is a continuum of consumers, $Q(t)$ is also the measure of consumers who adopt by time $t$.

By switching at time $t$, the seller expects a payoff of

$$
e^{-r t} Q(t) \pi^{\star}
$$

During the period when the seller is indifferent, this must be constant in $t$. It follows that

$$
Q(t)=Q(0) e^{r t}
$$

Solving $Q(T)=1$, where $Q(t)$ is given by (2), we get

$$
Q(0)=e^{-r T},
$$

and so

$$
Q(t)=\exp (r(t-T)) .
$$

A consumer who plans to adopt at time $t$ expects a discounted payoff of

$$
\begin{aligned}
& \rho e^{-r t} \frac{1}{r}\left(\mu^{\circ}-s\right)+ \\
+ & (1-\rho) \int_{t}^{\infty} e^{-r x}\left((F(x)-F(t))\left(\mu^{\star}-s\right)+(1-F(x))\left(\mu^{\circ}-s\right)\right) d x .
\end{aligned}
$$

The first term represents the case when the seller is of type L, in which case the consumer will enjoy zero price at all times after adoption. The second term corresponds to the case of an $\mathrm{H}$ type seller. With probability $F(t)$, the seller will have switched to pay mode, in which case the consumer strictly prefers not to adopt. With probability $1-F(t)$, price is still zero and the consumer adopts. At any time $x$ subsequent to adoption, with probability $(F(x)-F(t)) /(1-F(t))$ the seller will have switched to pay mode, in which case the buyer receives a net flow of $\mu^{\star}-s$ (a negative flow); whereas, with probability $(1-F(x)) /(1-F(t))$, the seller is still selling at zero price, yielding the consumer a positive utility flow of $\mu^{\circ}-s$. 
During the period when consumers are indifferent concerning adoption time, this expression must be constant in time. Taking the derivative with respect to $t$ and equating to zero we get

$$
\begin{gathered}
-\rho e^{-r t}\left(\mu^{\circ}-s\right)-(1-\rho)(1-F(t)) e^{-r t}\left(\mu^{\circ}-s\right)+ \\
+(1-\rho) \int_{t}^{\infty} e^{-x t}\left(s-\mu^{\star}\right) f(t) d x=0,
\end{gathered}
$$

where $f(t)$ is the density function corresponding to $F(t)$. Simplifying, we get

$$
\left(\mu^{\circ}-s\right)(1-\rho) F(t)+\left(s-\mu^{\star}\right)(1-\rho) \frac{1}{r} f(t)-\left(\mu^{\circ}-s\right)=0 .
$$

Solving with respect to $F(t)$, we get

$$
F(t)=\frac{1}{1-\rho}\left(1-\exp \left(\frac{\mu^{\circ}-s}{s-\mu^{\star}} r t\right)\right),
$$

Equating $F(t)=1$ and solving with respect to $t$ we get

$$
T=-\frac{\left(s-\mu^{\star}\right) \ln \rho}{\left(\mu^{\circ}-s\right) r}
$$

Substituting in (4) and simplifying, we get

$$
F(t)=\frac{1}{1-\rho}\left(1-\exp \left(\frac{\ln \rho}{T} t\right)\right),
$$

The expressions in the proposition follow. Specifically, $\theta(t)$ is given by the derivative of $F(t)$ with respect to $t$ divided by $1-F(t)$; and $\lambda(t)$ is given by the derivative of $Q(t)$ with respect to $t$ divided by $1-Q(t)$. 


\section{References}

Bagwell, Kyle (1987), "Introductory Price as a Signal of Cost in a Model of Repeat Business," Review of Economic Studies 54, 365-384.

Bagwell, Kyle, and Michael H Riordan (1991), "High and Declining Prices Signal Product Quality," American Economic Review 81, 224-239.

Bass, Frank M (1969), "A New Product Growth Model for Consumer Durables," Management Science 15, 215-227.

Cabral, Luís M B, and Michael H Riordan (1994), "The Learning Curve, Market Dominance and Predatory Pricing," Econometrica 62, 1115-1140.

Cabral, Luís M B, David Salant, and Glenn Woroch (1999), "Monopoly Pricing with Network Externalities," International Journal of Industrial Organization 17, 199-214.

Chen, Y, and R W Rosenthal (1996), "Dynamic Duopoly with Slowly Changing Customer Loyalties," International Journal of Industrial Organization 14, 269-296.

David, Paul A. (1969), "A Contribution to the Theory of Diffusion," Research Center in Economic Growth Memorandum No. 71, Stanford University.

Davies, Stephen (1979), The Diffusion of Process Innovations, Cambridge: Cambridge University Press.

Fudenberg, Drew, and Jean Tirole (1983), "Learning-by-Doing and Market Performance," Bell Journal of Economics 14, 522-530.

Geroski, Paul (2000), "Models of Technological Diffusion," Research Policy 29, 603-25.

Gerstner, Eitan, and James D Hess (1990), "Can Bait and Switch Benefit Consumers?," Marketing Science 9, 114-124.

Griliches, Zvi (1957), "Hybrid Corn: An Exploration in the Economics of Technological Change," Econometrica 25, 501-522.

Janssen, Maarteen C W, and Santanu Roy (2002), "Dynamic Trading in a Durable Good Market with Asymmetric Information," International Economic Review 43, $257-282$.

JENSEN, RICHARD (1982), "Adoption and diffusion of an innovation of uncertain profitability," Journal of Economic Theory 27, 182-193.

Judd, Kenneth L, And Michael H Riordan (1994), "Price and Quality in a New Product Monopoly," Review of Economic Studies 61, 773-789.

Klemperer, Paul (1995), "Competition when Consumers have Switching Costs: An Overview with Applications to Industrial Organization, Macroeconomics, and International Trade," Review of Economic Studies 62, 515-539. 
Lazear, Edward P (1995), "Bait and Switch," Journal of Political Economy 103, 813830.

Milgrom, Paul R., And John Roberts (1986), "Price and Advertising Signals of Product Quality," Journal of Political Economy 94, 796-821.

Noldecke, Georg, and Eric van Damme (1990), "Signalling in a dynamic labor market," Review of Economic Studies 57, 1-23.

Radner, R, and T J Richardson (2003), "Monopolists and Viscous Demand," Games and Economic Behavior 45, 442-464.

Radner, Roy (2003), "Viscous Demand," Journal of Economic Theory 112, 189-231.

Rosenthal, Robert W (1982), "A Dynamic Model of Duopoly with Customer Loyalties," Journal of Economic Theory 27, 69-76.

Rosenthal, Robert W (1986), "Dynamic Duopoly with Incomplete Customer Loyalties," International Economic Review 27, 399-406.

Spence, A Michael (1981), "The Learning Curve and Competition," Bell Journal of Economics 12, 49-70.

Swinkels, Jeroen M (1999), "Education Signalling with Preemptive Offers," Review of Economic Studies 66, 949-970.

Wilkie, William L, Carl F Mela, and Gregory T Gundlach (1998), "Does 'Bait and Switch' Really Benefit Consumers? Advancing the Discussion," Marketing Science 17, 290-293. 